\title{
How personalized and socialized power motivation facilitate antisocial and prosocial decision-making
}

\author{
Joe C. Magee ${ }^{a}$, Carrie A. Langner ${ }^{b}$ \\ a Robert F. Wagner Graduate School of Public Service, New York University, 295 Lafayette Street, 2nd Floor, New York, NY 10012, USA \\ ${ }^{\mathrm{b}}$ Department of Psychology and Child Development, California Polytechnic State University, San Luis Obispo, CA 93407, USA
}

\section{A B S T R A C T}

In two studies, we investigate the effects of individuals' power motivation on decisionmaking. We distinguish between two types of power motivation [McClelland, D. C. (1970). The two faces of power. Journal of International Affairs, 24, 29-47; Winter, D. G. (1973). The power motive. New York: The Free Press] and demonstrate that both types of power motivation facilitate influential decision-making but that each type plays a different role in different contexts. In a conflict context (Study 1), individuals' personalized (selfserving) power motivation was associated with antisocial decisions, and in a healthcare context (Study 2), individuals socialized (other-serving) power motivation was associated with prosocial decisions. Furthermore, the type of power motivation elicited in each context was associated with less perceived need to deliberate over the relevant policy decision. In separating out the independent effects of each type of power motivation, we are able to explain more variance in decision-making behavior across various contexts than in models using aggregate power motivation (personalized plus socialized).
A R T I C L E I N F O

\section{Keywords:}

Power motive

Motivation

Decision-making

Prosocial

Antisocial

Deliberation

Motives

Striving

Needs

Desires

\section{Introduction}

Individuals vary in the extent to which they desire to influence others and gain social status. This need for power, or power motivation, can only be satisfied when one is able to make decisions or take actions that affect others' lives (McClelland, 1975; Winter, 1973; Winter, 1992), and only some situations present opportunities to have this kind of impact. People in policy-making positions-political leaders and their advisors-have such opportunities all the time, and their power motivation is an important predictor of a wide range of behavior and accomplishments while in office (Ferguson \& Barth, 2002; Hermann, 1980; Winter, 2002, 2005). Political leaders' power motivation has been connected not only to military aggression and unilateral policy-making (Hermann, 1980; Winter, 2002) but also to positive impressions of their service and significant achievements (Ferguson \& Barth, 2002; Winter, 1987). The literature on ordinary individuals parallels these assessments of political leaders: power motivation has been linked, on the one hand, to a number of depraved behaviors (Winter, 1973, 2000) and, on the other hand, to self-selecting into helping professions (Winter \& Stewart, 1978). Despite these disparate findings, little is known about the role that power motivation plays in the decision-making processes that lead to these varied outcomes.

We address this gap in the literature first by noting an important distinction that has been neglected in recent research on power motivation (but see Harms, Roberts, \& Wood, 2007). We note that the motivation for power can be conceptualized as two separable desires corresponding to distinct kinds of influence: a desire to influence for self-serving and even antisocial 
ends, and a desire to influence for other-serving or prosocial ends (McClelland, 1970, 1975, 1985; McClelland \& Wilsnack, 1972; Winter, 1973; Winter \& Stewart, 1978). The current research builds on this distinction by proposing that although all people who are motivated by power seek to have influence, they can differ in the kinds of decisions they make and actions they take to have their influence. One type of power motivation drives individuals toward decisions that serve others' interests, and another type of power motivation drives individuals toward decisions that serve their own interests often at the expense of the interests of others. Second, we explore how, in different contexts, specifying which type of power motivation is relevant is crucial in understanding the role of power motivation in the decision-making process.

\section{Contrasting effects of power motivation}

Power motivation has been associated primarily with assertive, aggressive, and reprehensible behaviors and outcomes (Winter, 2000). Specifically, power motivation is related negatively to making concessions during conflict resolution (Langner \& Winter, 2001) and positively to assertiveness in friendships (McAdams, Healy, \& Krause, 1984), sexual aggression (Winter, 1973; Zurbriggen, 2000), extreme risk taking (McClelland \& Watson, 1973), and, for US presidents, engagement in war (Winter, 1987). Although it typically has been cast in a dark shadow, some have argued that the motivation for power can drive prosocial influence as well. In these conceptualizations of power motivation, research has focused increasingly on the moderating effects of other individual difference variables. One hypothesis has been that a strong inhibition tendency, or activity inhibition, provides a check on impulsive, antisocial behavior associated with high power motivation (McClelland \& Wilsnack, 1972; Schultheiss \& Brunstein, 2002), steering individuals toward prosocial behavior (McClelland, 1985, pp. 297-302; Spangler \& House, 1991). A second hypothesis has been that a high sense of responsibility combined with a strong power motive creates a desire for prosocial influence (Winter, 1988; Winter \& Barenbaum, 1985). A third hypothesis relates to a gender difference in the manifestation of power motivation, asserting that women use their power motivation for more prosocial ends than do men (McClelland, 1975, pp. 4758; McClelland, 1985, pp. 280-282; Winter, 1988; Winter \& Barenbaum, 1985; Winter \& Stewart, 1978). These three approaches all aim to explain why some individuals with strong power motivation do not exert negative influence and sometimes even strive to help others.

We adopt a different approach, one that is based not on moderators but rather on the separation of two types of power motivation (McClelland, 1970; Winter, 1973). This approach suggests that within power motivation, there exists more than one drive, similar in the desire to have influence but divergent in their ultimate consequences. Our goals in the current manuscript are to continue to develop this theoretical distinction between two types of power motivation and to test their associations with various decision-making processes.

\section{Socialized versus personalized power motivation}

McClelland and Winter, along with their respective colleagues, have independently pursued the notion that the motivation for power has two distinct components (McClelland, 1970, 1975, 1985; McClelland \& Wilsnack, 1972; Winter, 1973; Winter \& Stewart, 1978). Winter and colleagues (Winter, 1973; Winter \& Stewart, 1978) have argued that an egoistic, at times antisocial, desire for power and influence is separable from a concern with avoiding the depraved aspects of power and instead wanting to use influence for others' benefit. Similarly, McClelland and Wilsnack (1972) have found that one can desire to have influence over others either for self-serving, "personalized," reasons, or for other-serving, "socialized," reasons. Both Winter's and McClelland's distinctions are based on a differentiation of the outcomes that power-motivated individuals seek through their influence, outcomes that differ in their regard for others' welfare (see Thomas, Goleman, \& Goldstein, 1972; Winter, 1992 to compare the nearly identical coding schemes). This interpretation is consistent with findings that personalized power motivation is positively related to the acquisition of prestigious possessions (Winter, 1973) and elevated testosterone after dominating an opponent in a competitive game (Schultheiss, Campbell, \& McClelland, 1999), whereas socialized power motivation is positively related to ratings of oneself as a responsible individual and to selecting a teaching profession for one's career (Winter \& Stewart, 1978).

In previous research, personalized and socialized power motivation scores have been derived by dividing aggregate power motivation into these two types. Thus, both types of power motivation are necessarily correlated with the aggregate score (McClelland \& Watson, 1973; Winter \& Stewart, 1978). Conceptually, this means that individuals with high socialized power motivation and individuals with high personalized power motivation have a stronger desire to influence others than do individuals who score low in both types of power motivation; it is what they hope to achieve through their influence (personalized versus socialized ends) that distinguishes them. In relation to each other, personalized and socialized power motivation are theoretically independent. To illustrate this independence, consider three individuals, all of whom decide to pursue careers in politics. One of these individuals, who is high in socialized power motivation but not personalized power motivation, pursues this career to improve the welfare of a constituent group. Another, who is high in personalized power motivation but not socialized power motivation, seeks political office to achieve recognition and to coerce others into benefiting him. The other individual, high in both types of power motivation, is motivated both by the promise of helping others and by the trappings of political office. (An individual low in both types of power motivation presumably would choose another career in which influence is unimportant.) 
Although power motivation does affect long-term outcomes such as professional positions (McClelland \& Boyatzis, 1982; Winter, 1973), it also affects behavior in the near term. Our focus is on a relatively unexplored aspect of power motivation: how different types of power motivation affect decision-making processes and choices in different types of situations. Some decisions are clearly embedded within contexts focused on the welfare of others (e.g., education, healthcare), whereas other decisions are embedded within contexts that highlight self-interest and conflict (e.g., financial markets, war). For example, a political leader might have to decide whether or not to escalate a conflict during an international crisis, or she might need to consider a health policy that is expected to reduce mortality rates. In these situations, understanding a decision-maker's desire to have influence on others, or power motivation, is only a first step in predicting her policy choices; understanding the strength of her personalized power motivation in the international conflict and, in the healthcare context, the strength of her socialized power motivation, may be even more important.

\section{Different contexts elicit different types of motivation}

Like other features of the person, motivation drives behavior based on its interaction with aspects of the situation (Brunstein \& Maier, 2005; Fodor, Wick, \& Hartsen, 2006; Maner, Gailliot, Butz, \& Peruche, 2007; Mischel \& Shoda, 1995; Roberts \& Pomerantz, 2004; Shah, Higgins, \& Friedman, 1998). Situations vary in the extent to which they "pull" or elicit motivational drives and offer incentives compatible with satisfying a given motive (Schultheiss, 2001). In the current manuscript, we focus on situations that we expect will elicit either personalized or socialized power motivation, and we assume that the context must elicit one of these types of power motivation for it to drive the decision-making process. In these motive-eliciting contexts, we expect that individuals with a high level of the elicited type of power motive will make decisions more consistent with satisfying that motive than will individuals with a low level of the motive. Specifically, we hypothesize that in contexts characterized by competition and conflict, personalized power motivation will predict a preference for escalating the conflict, and in contexts associated with caring for others' well-being, socialized power motivation will predict a preference for maximizing positive impact on others.

In addition to affecting one's outcome preferences and decisions, we hypothesize that power motivation is associated with the process of making the decision as well. Before choosing how to respond in many situations, individuals have some amount of time to think over the implications of different potential responses, to contemplate whether or not various options are desirable. We use the term deliberation to describe this process of considering one's options and the related processes of seeking additional time or information before deciding how to respond. One direct implication of the notion that situations can elicit motives is that, once a motive has been elicited, the motivational drive might help reduce the perceived need to deliberate by directing the individual toward a motive-satisfying response. Thus, we hypothesize that socialized power motivation will reduce the perceived need to deliberate in contexts in which the focus is on others' well-being, and personalized power motivation will do the same in situations rife with conflict.

\section{Overview of studies}

In two studies, we examine our hypotheses that socialized and personalized power motivation guide individuals' perceived need to deliberate as well as their ultimate decisions in contexts that elicit one of these two types of power motivation. We measure participants' decision-making behavior in two engaging simulations that reflect complicated and consequential decision-making situations in real life. In Study 1, a simulation of the Cuban Missile Crisis, we predict that personalized power motivation will be associated with preferences for less deliberation and for escalating the conflict and that, in this conflict situation, personalized power motivation will be a more effective predictor of decision-making than will aggregate power motivation (socialized plus personalized).

In Study 2, participants role-play a Food and Drug Administration decision-maker and are charged with deciding whether or not to approve a new drug for the market. The clinical trials have shown that the drug, on balance, benefits society; thus, we predict that participants high in socialized power motivation will perceive less need for deliberation and will be more likely to approve the drug than will participants low in socialized power motivation. Furthermore, in Study 2, we test the predictive validity of our hypothesized distinction between socialized and personalized power motivation against the three previously hypothesized moderators of aggregate power motivation discussed above: activity inhibition, sense of responsibility, and gender.

\section{Overview of methods}

The motivation for power can operate implicitly or explicitly, much like other basic motivational constructs, such as affiliation-intimacy (e.g., McAdams, 1982) and achievement (e.g., McClelland, 1961) motivation. The implicit and explicit forms of power motivation are measured differently, are largely independent of each other (Brunstein \& Maier, 2005; Kehr, 2004; King, 1995; but see Emmons \& McAdams, 1991), and can yield different effects (e.g., Spangler, 1992; for reviews, see McClelland, Koestner, \& Weinberger, 1989; Schultheiss, 2001; Woike, Mcleod, \& Goggin, 2003). The implicit power motive is typically measured with an adapted form of the Thematic Apperception Test or other written responses to a motive-eliciting stimulus or situation (Winter, 1991), and it affects the pleasure derived from activities that provide an incentive to 
satisfy the power motive (Koestner, Weinberger, \& McClelland, 1991; McClelland et al., 1989; Pang \& Schultheiss, 2005; Schultheiss \& Pang, 2007). Explicit power motivation is self-reported and guides individuals' responses such that their decisions are aligned with their motivation (McClelland et al., 1989).

This implicit versus self-reported distinction has been important in understanding the conditions under which power motivation predicts different kinds of outcomes (Winter, John, Stewart, Klohnen, \& Duncan, 1998); however, it is not well understood with respect to the personalized and socialized types of power motivation. We expected that in a strong, motive-arousing context, implicit power motivation could affect decision-making in a manner similar to self-reported power motivation. Thus, we used both implicit and self-report measures of power motivation developed in prior research to predict decision-making in contexts that we expected would elicit either personalized or socialized power motivation. In Study 1, we adapted a technique used by Peterson, Winter, and Doty (1994) and Langner and Winter (2001), measuring participants' motivation from their drafts of a letter responding to Soviet Premier Nikita Khrushchev in the context of a simulation of the Cuban Missile Crisis. In Study 2, we derived participants' motivation from lists of self-reported personal strivings (Emmons, 1989, 1997; Emmons \& McAdams, 1991; see also Igreja et al., 2000).

These measures also allowed us to score affiliation motivation. Affiliation motivation-a desire to have friendly relations with others-has been shown to relate to some kinds of prosocial behavior (e.g., Langner \& Winter, 2001) and thus was important to include as a control variable in our analyses. The vast impact of the decisions that participants made in the scenarios led us to expect that power motivation (personalized in the conflict context and socialized in the healthcare context) would be a more effective predictor of decision-making than would affiliation motivation.

\section{Study 1: Escalating conflict in the Cuban Missile Crisis}

In the first study, participants were asked to generate a simulated series of reactions to Soviet Premier Nikita S. Khrushchev's letter written to US President John F. Kennedy on October 26, 1962, a defining moment during the Cuban Missile Crisis. We measured participants' socialized and personalized power motivation using a technique developed in prior work (Langner \& Winter, 2001; Peterson et al., 1994): participants drafted a letter replying to Premier Khrushchev, and we scored motive imagery in the body of the letter. Then, we presented participants with a number of specific policy response options associated with varying degrees of escalation, and participants were asked to indicate the advice they would give President Kennedy by rank ordering the policy options. Participants also indicated the extent to which they would advise President Kennedy to deliberate over this decision. We predicted that in this conflict context personalized power motivation would be associated with advice to engage in an aggressive response to escalate the conflict with the Soviet Union and not to deliberate extensively over the policy decision.

\subsection{Method}

\subsubsection{Participants}

Participants were 96 students and staff (63 women and 33 men; 40 Asian/Asian-American, 27 Caucasian, 11 Chicano/ Hispanic/Latino, 11 African-American, and 7 unknown) at an East Coast university who were offered $\$ 10$ in exchange for their participation. The median age of participants was 20 years.

\subsubsection{Design and procedure}

This experiment had two measured independent variables, socialized and personalized power motivation. The procedure was identical to Peterson et al. (1994); see also Langner and Winter, 2001, Study (2) except where specific details are provided. Participants first read an information sheet describing important events during the Cuban Missile Crisis, including President Kennedy's decision to create a naval blockade preventing the Soviet Union from delivering weapons to Cuba. Then, participants read an abbreviated version of Premier Khrushchev's letter to President Kennedy in which he warned the President about the consequences of the United States' actions and suggested that it was up to the President whether the conflict escalated or de-escalated. Following their reading of Khrushchev's letter, participants were asked to draft a reply to Premier Khrushchev on behalf of the President. The next page contained 15 lines on which to draft a letter addressed to Premier Khrushchev; the footer included a closing from President Kennedy. We derived participants' motivational scores from the text they wrote in these letters.

7.1.2.1. Coding letters for power motivation and affiliation motivation. Two independent coders first were trained in scoring motive imagery in running text (Winter, 1991) and then scored participants' letters from President Kennedy to Premier Khrushchev for affiliation motive imagery and power motive imagery. According to these rules, the following constitute affiliation motive images: (a) positive feelings toward others, (b) negative feelings about disruption of a friendly relationship, (c) companionate activities, and (d) solicited nurturing acts. The following were scored as power motive images: (a) forceful behaviors that affect others, (b) controlling or influencing others, (c) impressing others, (d) arousing emotions in others, (e) concern for reputation or position, and (f) giving unsolicited help to others. To capture the different forms of power motivation, the power motive images were classified further as personalized or socialized power motivation. An image was coded as socialized power motivation if it (a) involved a goal that benefits others; (b) expressed doubt about the ability to influence, 
control, or impress; or (c) indicated that power is dangerous, deceptive, or flawed. All other power motive images were coded as personalized power motivation; the sum of personalized and socialized power motivation images equaled the total number of power motive images for each subject (Winter, 1992). The reliability across judges was high for affiliation motivation and personalized and socialized power motivation ( $\alpha \mathrm{s}>.84$ ). The judges resolved all disagreements through discussion. Fifty-five percent of the power motive images were personalized, and $45 \%$ were socialized. None of the motivation scores was significantly correlated with the length of the letters (i.e., word count); therefore, we used the raw motivation scores instead of standardized scores in all analyses (Schultheiss \& Pang, 2007).

One potential concern about measuring motivation directly from text written within the conflict context is that the motivation measures themselves might have reflected participants' preferences for escalation or de-escalation, which could artificially inflate the relationship between this measure of participants' motivation and the policy response options that they rank ordered after writing the letter. To control for this we asked two coders to score each letter on a 7-point scale for the extent to which the participant indicated that the US would de-escalate or escalate the conflict $(1=$ extreme de-escalation; $7=$ extreme escalation). These scores measuring escalation in the letter to Khrushchev were averaged $(\alpha=.81)$ for use as a control variable in analyses.

7.1.2.2. Dependent measures. After writing their letters, participants were asked to give President Kennedy advice about the actions the US should take in response to Khrushchev. Participants then rank ordered the following seven policy response options (from Langner \& Winter, 2001; Peterson et al., 1994) (1 = the best advice; 7 = the worst advice):

1. Ignore Khrushchev; bomb the missile bases, and launch a full-scale US invasion to remove all offensive weapons and overthrow the Castro regime.

2. Ignore Khrushchev, and bomb the missile bases.

3. Ignore Khrushchev, and tighten the US blockade to include oil.

4. Ignore Khrushchev; leave the US blockade as it is, and wait.

5. Leave the US blockade as it is, but offer to negotiate with Khrushchev on the basis of his proposals.

6. Call off the blockade, and offer to negotiate with Khrushchev on the basis of his proposals.

7. Accept Khrushchev's proposals as they stand, and call off the blockade.

After ranking the policy options, participants responded to four questions measuring the extent to which they would advise President Kennedy to deliberate over the policy response: "To what extent is it advisable to defer the decision about how to respond until further evidence can be collected?" ( $1=$ not at all; $9=$ extremely), "How quickly would you advise the President make his decision?" ( 1 = not at all; $9=$ extremely), "To what extent is it advisable to seize the opportunity to respond now?" ( 1 = not at all; 9 = extremely), and "To what extent should the decision about how to respond be expedited?" $(1=$ not at all; $9=$ very $m u c h)$. The last three questions were reverse-scored. Finally, participants reported their demographic information and were debriefed and paid.

\subsection{Results}

\subsubsection{Preliminary analyses}

Six participants were removed from all analyses because they did not follow instructions in ranking the policy options. The four questions measuring advised deliberation were averaged $(\alpha=.72)$. The Policy Option rankings were reverse-scored, such that higher numbers represented stronger approval of the Policy Options. Although the policy option rankings are technically ordinal measures, they were decomposed into two variables approximating interval measures by averaging Policy Options 1-3 to create an advised escalation index and Policy Options 5-7 to create an advised de-escalation index. ${ }^{1}$ The descriptive statistics and intercorrelations for the measured variables are presented in Table 1.

\subsubsection{Regression analyses}

We constructed general linear models comparing whether aggregate power motivation or personalized power motivation, controlling for socialized power motivation, was a more effective predictor of advice to deliberate over the policy response and to escalate the conflict. We included affiliation motivation and gender as additional control variables, and because the measure of escalation from participants' letter to Khrushchev was indeed correlated with the dependent measures (see Table 1), we also included it as a control variable. The results of these models in Table 2 are consistent with our hypotheses: after separating socialized and personalized power motivation, personalized power motivation explained more variance in participants' advice to deliberate over the decision and to select an escalatory policy response than did aggregate power motivation (compare the $R^{2}$ in models 2 versus 1 and 4 versus 3). Specifically, personalized power motivation was associated with advising less deliberation and greater escalation. Only the models including the predicted independent effects of socialized and personalized power motivation (Models 2 and 4) will be discussed further.

\footnotetext{
${ }^{1}$ We also analyzed the policy response rankings in seven separate ordinal logit models. Consistent with the results using the escalation and de-escalation indexes, these models revealed that personalized power motivation was positively associated with preferences for two escalation options: Policy Options 1 $(p=.068)$ and $3(p=.017)$. Socialized power motivation was not significantly associated with any options.
} 
Table 1

Descriptive statistics and intercorrelations, Study 1

\begin{tabular}{|c|c|c|c|c|c|c|c|c|c|c|c|}
\hline & Variable & $M$ & $S D$ & 1 & 2 & 3 & $4 a$ & $4 b$ & 5 & 6 & 7 \\
\hline 1. & Female & 0.64 & 0.94 & - & -.00 & -.05 & .03 & -.04 & .02 & -.05 & $-.21^{*}$ \\
\hline 2. & Escalation in letter to Khrushchev & 3.63 & 0.77 & & - & $-.44^{* * *}$ & .14 & -.00 & .07 & $.26^{*}$ & $-.21^{*}$ \\
\hline 3. & Affiliation motivation & 0.74 & 0.74 & & & - & -.01 & -.11 & -.09 & .00 & .10 \\
\hline 4a. & Personalized power motivation & 0.72 & 0.75 & & & & - & $-.40^{* * *}$ & $-.25^{*}$ & $.32^{* *}$ & -.12 \\
\hline $4 \mathrm{~b}$. & Socialized power motivation & 0.59 & 0.62 & & & & & - & .07 & -.13 & .08 \\
\hline 5. & Advised deliberation & 4.55 & 1.39 & & & & & & - & $-.21^{*}$ & .05 \\
\hline 6. & Advised escalation in policy response options & 2.54 & 0.92 & & & & & & & - & $-.50^{* * *}$ \\
\hline 7. & De-escalation & 4.80 & 0.97 & & & & & & & & - \\
\hline
\end{tabular}

Note. $N=90$. Female is a binary variable for which $M$ represents the proportion of female participants.

$p \leqslant .05$.

${ }^{* * *} p<.01$.

${ }^{* * *} \quad p<.001$.

Table 2

Comparison of OLS regression analyses of advised deliberation and advised escalation on aggregate power motivation versus socialized and personalized power motivation in a simulation of the Cuban Missile Crisis, Study 1

\begin{tabular}{|c|c|c|c|c|}
\hline & \multicolumn{2}{|c|}{ Advised deliberation } & \multicolumn{2}{|c|}{ Advised escalation in policy response options } \\
\hline & 1 & 2 & 3 & 4 \\
\hline Female & $-0.02(0.16)$ & $-0.03(0.16)$ & $0.04(0.10)$ & $0.05(0.10)$ \\
\hline Escalation in letter to Khrushchev & $0.11(0.21)$ & $0.14(0.21)$ & $0.36^{* *}(0.14)$ & $0.33^{*}(0.13)$ \\
\hline Affiliation motivation & $-0.16(0.22)$ & $-0.12(0.22)$ & $0.19(0.14)$ & $0.15(0.14)$ \\
\hline Aggregate power motivation & $-0.39(0.20)$ & & $0.22(0.13)$ & \\
\hline Personalized power motivation & & $-0.53^{*}(0.21)$ & & $0.34^{*}(0.14)$ \\
\hline Socialized power motivation & & $-0.12(0.26)$ & & $-0.01(0.16)$ \\
\hline$R^{2}$ & .05 & .08 & .12 & .17 \\
\hline
\end{tabular}

Note. $N=90$. Unstandardized coefficients with standard errors in parentheses. Aggregate Power Motivation $=$ Socialized Power Motivation + Personalized Power Motivation.

${ }^{*} p<.05$

** $p<.01$.

7.2.2.1. Advised deliberation. In Model 2, personalized power motivation was negatively related to advised deliberation in this conflict context, $p=.016$, lending support to the hypothesis that deliberation would be reduced in contexts eliciting one of the two types of power motivation. Socialized power motivation, affiliation motivation, escalation measured in the response letters to Khrushchev, and gender all were not significant predictors of advice to deliberate $(p s>.5)$.

7.2.2.2. Advised escalation in policy response options. Also supportive of our hypotheses, Model 4 reveals that, even after accounting for the extent to which participants wrote about escalating the conflict in their letters to Khrushchev, $p=.015$, personalized power motivation was positively related to escalation in the policy response options, $p=.013$. As we expected, socialized power motivation, gender, and affiliation motivation were unrelated to escalation in the policy response options $(p s>.27)$.

7.2.2.3. Advised de-escalation in policy response options. Regressing de-escalation in the policy response options on the same independent variables, as we expected, personalized power motivation was not significant, $b=-0.10, S E=0.15, p=.521$. Neither socialized power motivation, $b=0.06, S E=0.18, p=.723$, nor affiliation motivation, $b=0.02, S E=0.15, p=.521$, were related to de-escalation; however, the extent to which participants wrote about escalation in their letters to Khrushchev showed a negative trend with de-escalation in the policy response options, $b=-0.25, S E=0.15, p=.098$, and there was a marginally significant tendency for women to favor de-escalation more than for men, $b=0.21, S E=0.11, p=.057$. This gender result is consistent with previous research, which shows that women engage in more cooperative behavior than men in conflict situations (Walters, Stuhlmacher, \& Meyer, 1998).

In a model examining the preference for ignoring Khrushchev and leaving the naval blockade in place (Policy Option 4), although there were no statistically significant effects of the independent variables, personalized power motivation trended toward a negative relationship with this option, $b=-0.36, S E=0.20, p=.079$ (for other independent variables, $p s>.2$ ).

\subsection{Discussion}

This study demonstrates that separating out personalized and socialized power motivation provides a more comprehensive explanation for two aspects of individuals' decision-making preferences-their desire to deliberate over the decision as well as their preferences for different types of outcomes-than does the traditionally aggregated power motivation score in 
an escalating conflict. As we predicted, in this context where one's advice to aggress would have an aversive impact on the other party in a conflict, personalized power motivation predicts preferences for escalation. We also found support for the hypothesis that personalized power motivation reduces the perceived need for deliberation about a consequential decision. The predicted effects of personalized power motivation and the lack of any significant effects for socialized power motivation in this conflict context are consistent with the notion that different contexts differentially elicit each type of power motivation. In selecting a different situation in the next study, a healthcare scenario, we were able to test whether a context typically associated with consideration for the well-being of others would elicit the effects of socialized power motivation on decision-making.

\section{Study 2: Approving a life-saving drug for the FDA}

In Study 2, we moved from an international conflict simulation, which provided an opportunity to satisfy personalized power motivation by escalating the conflict, to a healthcare context, which provided an opportunity to satisfy socialized power motivation by making a decision that would improve and save lives. We used another previously validated method to measure power motivation by asking participants to report explicitly their strivings in their personal lives (Emmons \& McAdams, 1991). To check that decision-making in this context was indeed determined by socialized power motivation and not by the interaction of aggregate power motivation and activity inhibition, sense of responsibility, or gender, we measured the latter three variables as well.

Power motivation can drive decision-making not only because individuals motivated by power can influence targets of their choices but also because they can impress others who notice their behavior and judge their social status (Winter \& Stewart, 1978). Although the results of Study 1 indicate that power motivation affects decision-making in private, in Study 2 we sought to test whether this association is even stronger in public. Thus, we manipulated whether participants were being judged for a leadership position by the others attending their session. The existing theory suggests that under these conditions, the association between power motivation and decision-making behavior would be stronger than under private conditions (Winter \& Stewart, 1978).

\subsection{Method}

\subsubsection{Participants}

Participants were 71 students and staff ( 41 women and 30 men; 28 Asian/Asian-American, 24 Caucasian, 11 AfricanAmerican, 4 Chicano/Hispanic/Latino, and 4 unknown) at a West Coast university who were offered $\$ 7$ in exchange for their participation. The median age of participants was 19 years.

\subsubsection{Overview and design}

This experiment had two measured independent variables-socialized and personalized power motivation-and one manipulated two-level independent variable, whether the participant believed his or her decisions would be judged by the other participants for a leadership position (public versus private).

8.1.2.1. Power motivation measure. Power motivation was measured by having participants list their personal strivings (Emmons, 1986, 1989; Emmons \& McAdams, 1991). Personal strivings are more general than goals with specific plans (e.g., yell at him) and more specific than motives (e.g., arouse emotions in others); strivings (e.g., let others know my feelings) reflect the goals that an individual is typically trying to accomplish. The present experiment was the first empirical test of whether or not socialized and personalized power motivation represented in personal strivings could be used to predict targeted, situation-specific behavior.

8.1.2.2. Public/private manipulation. In the public/private manipulation, participants were told either that their reported decisions would be viewed by other people who were judging their qualifications for a leadership position or that their responses would be kept confidential. This manipulation was designed to examine the extent to which the relationship between power motivation and decision-making depends on visibility to others judging an aspect of one's social status.

8.1.2.3. The scenario and task. We used a decision-making scenario and task developed by Tetlock and Boettger (1994). Participants were asked to play the role of a regulatory decision-maker for the Food and Drug Administration (FDA), which, they were told, was asked to consider whether or not to approve a new drug that prevents blood clots that lead to fatal heart attacks. Participants read their role, medical information about the drug, and the potential costs and benefits associated with choosing to approve the drug versus maintaining the status quo treatment on the market. Then, participants indicated the extent to which they would advise deliberating over the decision and whether or not they recommended approving the drug.

\subsubsection{Materials}

All participants read the role description, which informed them that they would be making regulatory decisions for the Food and Drug Administration regarding the introduction of a new drug called Carozile (see Tetlock \& Boettger, 1994). Then, 
participants were given a "factsheet" describing the hypothetical research findings about Carozile, which showed that it would save more lives than it would cost. The factsheet was adapted from Tetlock and Boettger (1994) and is contained in Appendix A.

\subsubsection{Procedure}

Participants completed the study in groups of between two and five people. They were led to believe that the session involved two different experiments, one about personal goals and one about management decisions. In fact, the two tasks were connected. Each session was randomly assigned to a public/private condition (i.e., within each session, participants were all in either the public or private condition). The instructions began by asking participants to generate 15 personal strivings in their everyday lives and write them on blank lines beginning "I typically try to..." (see Emmons, 1989).

8.1.4.1. Coding personal strivings for power motivation and affiliation motivation. The personal strivings were coded by two independent judges for affiliation and power motivation according to the same procedure used in Study 1 . The judges reliably distinguished affiliation and power motivation (Cohen's $\kappa=.81$ ). Ten percent of the strivings listed by all participants were coded as examples of power motivation, and $17 \%$ of the strivings were coded as affiliation motivation. The judges were able to distinguish reliably between socialized and personalized power motivation (Cohen's $\kappa=.82$ ). Of all the power strivings, $54 \%$ were personalized and $46 \%$ were socialized. Ninety-six percent of the instances of socialized power motivation were strivings for a goal that benefits other people. Selections of strivings for a participant high in socialized power motivation and for a participant high in personalized power motivation are presented in Table 3. A participant's personalized and socialized power motivation scores were the count of personalized power strivings and count of socialized power strivings, respectively.

To test whether the previously discussed possible moderators of aggregate power motivation explained prosocial decision-making, one coder scored participants' personal strivings for activity inhibition by counting the instances of the word "not" (McClelland \& Wilsnack, 1972) and sense of responsibility by following the coding scheme developed by Winter and Barenbaum (1985).

8.1.4.2. Role instructions, knowledge test, and manipulation check. After listing their strivings, participants read their role instructions and the Carozile "factsheet." Participants completed a 5-item knowledge test (see Appendix B) to insure they paid attention to the "factsheet" on Carozile (Tetlock \& Boettger, 1994) and then the dependent measures. Participants responded on 9-point scales to four questions measuring perceptions of the need to deliberate over the decision which were adapted from Study 1 to this decision-making context. To measure their final decision, participants were asked, "Do you recommend putting the drug Carozile on the market?" (yes/no).

Finally, participants were asked for demographic information, probed for suspicion about a connection between the personal striving task and the decision about Carozile, debriefed, paid, and dismissed.

\subsection{Results}

\subsubsection{Preliminary analyses}

Two participants were removed from all analyses: one participant did not complete the dependent measures, and one participant indicated suspicion about a connection between the personal strivings task and the Carozile drug scenario. The remaining analyses were conducted with a final sample of 69 participants. Public/private condition did not interact significantly with either socialized or personalized power motivation ( $p s>.4$ ). Thus, we did not find support for the hypothesis that power motivation's facilitation of decision-making is stronger when others are judging the decision-maker's leadership potential. Public/private condition was included as a covariate in all remaining analyses but will not be discussed further.

8.2.1.1. Knowledge test. On the Carozile knowledge test, 39 participants scored 4 out of 5 , and the remainder of participants scored 5. Most of the errors were due to the second question, which asked participants to estimate the likelihood that sci-

Table 3

Selection of strivings for participants high in socialized versus personalized power motivation, Study 2

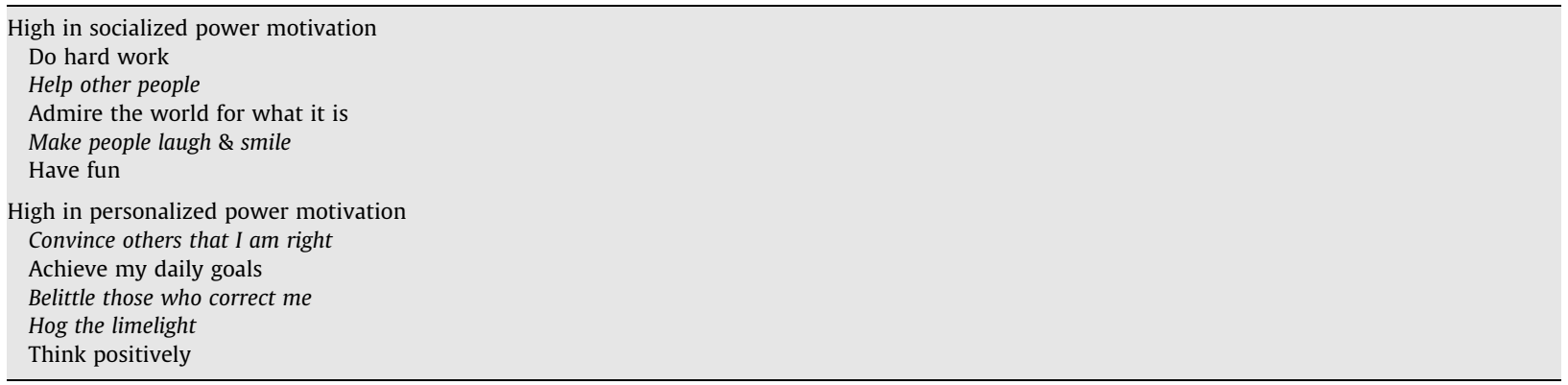

Note. Italicized strivings were coded for the target type of power motivation. These participants scored greater than one standard deviation above the mean for the target type of power motivation. Strivings are five examples selected from each participant's full set of 15. 
Table 4

Descriptive statistics and intercorrelations for measured variables, Study 2

\begin{tabular}{|c|c|c|c|c|c|c|c|c|c|c|}
\hline & Variable & $M$ & $S D$ & 1 & 2 & 3 & $4 a$ & $4 b$ & 5 & 6 \\
\hline 1. & Female & 0.58 & 0.50 & - & .10 & .01 & -.17 & .10 & -.09 & .17 \\
\hline 2. & Knowledge test & 4.44 & 0.50 & & - & -.04 & -.14 & .21 & -.04 & .12 \\
\hline 3. & Affiliation motivation & 2.54 & 1.45 & & & - & -.10 & $.26^{*}$ & -.10 & .04 \\
\hline 4a. & Personalized power motivation & 0.67 & 0.98 & & & & - & .01 & .19 & -.17 \\
\hline $4 \mathrm{~b}$. & Socialized power motivation & 0.80 & 1.51 & & & & & - & $-.26^{*}$ & $.31^{*}$ \\
\hline 5. & Advised deliberation & 5.34 & 1.42 & & & & & & - & $-.66^{* * *}$ \\
\hline 6. & Drug approval recommendation & 0.33 & 0.48 & & & & & & & - \\
\hline
\end{tabular}

Note. $N=69$. Female and drug approval are dichotomous variables for which $M$ represents the proportion of participants who responded in the affirmative. ${ }^{*} p<.05$.

$p<.001$.

entists would discover a superior drug in the future. Thus, we interpreted the knowledge test score as a measure of participants' level of certainty about the drug's efficacy and included it as a covariate in all analyses.

\subsubsection{Regression analyses}

The descriptive statistics for the measured variables and the correlations between them are presented in Table 4. We ran four regression models, two linear models predicting advised deliberation $(\alpha=.65)$ and two logistic models predicting the choice to approve Carozile ( 1 approval, $0=$ no approval). In all models, we included either aggregate power motivation or socialized and personalized power motivation, affiliation motivation, gender, public/private condition, and the knowledge test score as independent variables. These results, presented in Table 5, support our hypotheses (compare the $R^{2}$ in models 2 versus 1 and 4 versus 3 ). Aggregate power motivation was unrelated to either deliberation or approval of the drug. Instead, as we predicted in this healthcare context, after separating socialized and personalized power motivation, socialized power motivation explained more variance in the decision-making measures. We explain the models testing for the independent effects of socialized and personalized power motivation (Models 2 and 4) below.

8.2.2.1. Advised deliberation. In support of our hypothesis about the perceived need for deliberation, Model 2 in Table 5 shows that socialized power motivation was associated with less preference for deliberation about the decision, $p=.026$, whereas personalized power motivation and deliberation were not significantly related, $p=.106$. Affiliation motivation, gender, and the knowledge test were not significantly related to deliberation ( $p s>.4)$.

8.2.2.2. Drug approval recommendation. Logistic regression of participants' decision to approve Carozile yielded results supportive of our hypotheses as well (see Table 5). Model 4 shows that participants higher in socialized power motivation were significantly more likely to introduce the drug to market than were participants lower in socialized power motivation, $p=.029$, and the coefficient for personalized power motivation was not statistically significant, $p=.161$. Affiliation motivation, gender, and the knowledge test were not related to this decision ( $p s>.3$ ).

8.2.2.3. Testing moderators of aggregate power motivation. We did not find any support for the previously theorized moderators of aggregate power motivation: activity inhibition, sense of responsibility, or gender. In models predicting deliberation and approval of the drug and including the covariates from the models in Table 5, aggregate power motivation did not interact significantly with gender ( $p=.660$ and .814$)$, activity inhibition $(p=.451$ and .367$)$, or sense of responsibility $(p=.129$ and .225).

\subsection{Discussion}

This study further emphasizes the importance of separating socialized and personalized power motivation. In a healthcare context, socialized power motivation was significantly associated with less perceived need for deliberation and greater likelihood of approval of the drug-a decision that, on balance, would save lives-even after controlling for a host of other variables such as gender and affiliation motivation, which have been associated with some kinds of prosocial behavior. Aggregating both types of power motivation completely masked the statistical relationship between socialized power motivation and decision-making. Moreover, socialized power motivation was a better predictor of decision-making than were previous conceptualizations of activity inhibition, sense of responsibility, or gender interacting with aggregate power motivation to produce prosocial decisions.

\section{General discussion}

These studies support the idea that power motivation consists of two separable desires to influence others that are based on distinct social outcomes. Personalized power motivation reflects an egoistic desire to make an impact on others with 
Comparison of regression analyses of advised deliberation and drug approval recommendation on aggregate power motivation versus socialized and personalized power motivation in a simulated healthcare context, Study 2

\begin{tabular}{|c|c|c|c|c|}
\hline & \multicolumn{2}{|c|}{ Advised deliberation $^{\mathrm{a}}$} & \multicolumn{2}{|c|}{ Drug approval recommendation ${ }^{\mathrm{b}}$} \\
\hline & 1 & 2 & 3 & 4 \\
\hline Female & $0.10(0.18)$ & $-0.02(0.17)$ & $0.37(0.28)$ & $0.27(0.29)$ \\
\hline Affiliation motivation & $0.11(0.12)$ & $-0.01(0.12)$ & $0.05(0.19)$ & $-0.06(0.20)$ \\
\hline Aggregate power motivation & $-0.01(0.10)$ & & $0.03(0.15)$ & \\
\hline Personalized power motivation & & $0.19(0.11)$ & & $-0.45(0.32)$ \\
\hline Socialized power motivation & & $-0.42^{*}(0.18)$ & & $0.77^{*}(0.35)$ \\
\hline$R^{2}$ & .06 & .16 & .07 & .21 \\
\hline
\end{tabular}

Note. $N=69$. Unstandardized coefficients with standard errors in parentheses. Aggregate Power Motivation $=$ Socialized Power Motivation + Personalized Power Motivation. All models also include the measure of certainty from the knowledge test and public/private condition as covariates; neither variable was significant in any of the models.

a OLS regression models.

b logistic regression models; $R^{2}$ is Nagelkerke $R^{2}$.

$p<.05$.

disregard for their interests, and socialized power motivation reflects a desire to make a prosocial impact on others. Whether or not each type of power motivation facilitates influential decision-making depends on the context in which individuals are making their decisions. We used two distinct contexts and a variety of decision-making measures to illustrate the role that the situation plays in eliciting the different types of power motivation and in facilitating the decisions that satisfy each type of motivation. Participants in Study 1 were confronted with a simulation of one of the most important international conflicts in US history, the Cuban Missile Crisis. In that context, personalized power motivation was associated with the pursuit of policy responses that escalated rather than reduced conflict with the Soviet Union. Study 2 used a simulated healthcare context in which participants made a decision about approving a drug that research indicated would save lives overall. In that context, participants with greater socialized power motivation were more likely to make the choice that would save the greatest number of lives, to put the new drug on the market. Beyond these effects of personalized and socialized power motivation on individuals' actual decisions, power motivation also facilitated decision-making in another way: it reduced the perceived need to deliberate before making the decision. In both studies, the type of power motivation elicited by the context was associated with a preference for less deliberation over the decision that was being made.

\subsection{Future directions}

In testing various alternative conceptualizations of how power motivation can drive prosocial behavior in Study 2 , we did not find that aggregate power motivation (personalized plus socialized power motivation) interacted with gender, activity inhibition, or a sense of responsibility to explain our results. Although future research might continue to explore moderators of power motivation, our findings suggest that work in this area could benefit from parsing socialized and personalized power motivation out of aggregate power motivation and considering their independent psychological effects. In emphasizing the difference between socialized and personalized power motivation, we see a number of opportunities for additional research.

\subsubsection{The relationship between personalized and socialized power motivation}

We described above that we conceptualize socialized and personalized power motivation as theoretically independent constructs, and in the current studies they were not strongly related to one another. However, in Study 1, the two types of power motivation were modestly, inversely related. This suggests that future work might uncover the conditions under which and populations in which the two types display a relationship with each other. It would also be interesting to know whether or not there are optimal power motivation profiles (e.g., high socialized, low personalized power motivation) related to individual performance in political careers or in public sector organizations. These potential advances notwithstanding, the two types of power motivation do not appear to be positively associated with each other; thus, aggregating them does not seem to be an appropriate research strategy. In fact, our results show that aggregating personalized and socialized power motivation can mask important relationships between power motivation and decision-making variables. Personalized and socialized power motivation have different effects in different contexts, and future research could benefit from measuring them separately.

\subsubsection{Person-environment fit}

Another future direction for research on power motivation would be to explore hypotheses derived from the literature on person-environment fit (Edwards, 2008; Pervin, 1968; Roberts \& Robins, 2004; Walsh, Craik, \& Price, 2000). For example, if motive-environment fit is important in providing opportunities for needs and desires to be satisfied, individuals with a strong implicit power motive might seek out situations in which they can influence other people (McClelland, 1985). These motive-consistent situations would provide incentives to satisfy individuals' motives, which would result in positive affect 
and satisfaction (Brunstein, Schultheiss, \& Grässmann, 1998; Emmons, Diener, \& Larsen, 1986; O’Reilly, Chatman, \& Caldwell, 1991; Schultheiss, 2001). Considering our findings in light of the framework of person-environment fit suggests that in their daily lives individuals with high personalized power motive would anticipate and experience more positive affect from making a self-interested impact on others, and individuals with high socialized power motive would experience these same positive affective states by taking beneficent action. One result of motive-environment fit is that the power motive manifests itself in the roles, types of organizations, and careers that individuals pursue (Harms, Roberts, \& Winter, 2006). Socialized power motive may guide people toward social service organizations and helping occupations, and personalized power motive may direct people toward occupations promoting aggressive strategy and forceful action (e.g., the military). Further, motive-environment fit could strengthen a particular motivational drive. As a result, motivation and environment could serve to reinforce each other in a corresponsive fashion over time (Roberts \& Pomerantz, 2004). Future longitudinal studies could investigate the dynamics of this kind of reinforcement process between individuals' environments and their personalized or socialized power motive.

\section{Conclusion}

Like the experience of power itself, the motivation for power is thought to have a profound effect on thought and behavior. Yet, little is known about how quick to make decisions individuals with high power motivation are in comparison to those with low power motivation. The power motivation of political leaders and ordinary people can give insight into the extent to which they will deliberate over decisions and make choices that will impact others' lives. But if we can dig deeper, understanding whether individuals want to serve others or serve themselves through their influence, we might be able to predict just what types of decisions they will make and whether they, and the people around them, would be better served if they deliberated more over the consequences of their actions.

\section{Acknowledgments}

We thank Maureen Belluscio, Daniel Menezes, Lisa Smith, and Lizzy Van Alstine for their help in coding the data for these studies.

\section{Appendix A. Presentation of carozile research findings, Study 2 (adapted from Tetlock \& Boettger, 1994)}

The drug under consideration is an anti-coagulant called Carozile. In experimental research, scientists have found that Carozile breaks up blood clots that, if left untreated, could lead to fatal heart attacks. This research also found a costly tradeoff to this benefit: Carozile can cause severe internal bleeding, which leads to strokes in certain patients. Unfortunately, research has been unable to identify what factors interact with the drug to cause the bleeding, so it is impossible to predict ahead of time who will suffer internal bleeding as a result of administering the drug. The best available clinical prediction is that between 300 and 900 more people at risk of this kind of heart attack will die each year if doctors do not administer Carozile to them but that 100-300 patients per year will die-patients who would not have died otherwise-due to administration of Carozile.

Carozile has no known pharmaceutical substitute for patients who would benefit from its anti-clotting effects. If these patients do not take Carozile, many of them would die. Although there is always a chance of discovering a better drug that would not be limited by the cost of some patients experiencing internal bleeding and strokes, the leading researchers in the field unanimously maintain that this is unlikely to happen anytime soon. The likelihood of significant breakthroughs, or even better evidence about how to predict who would experience internal bleeding from Carozile, in the next year is extremely low.

\section{Appendix B. Carozile knowledge test, Study 2 (adapted from Tetlock \& Boettger, 1994)}

Please answer all questions by circling the best answer. Base your answers only on the information you have read about Carozile.

1. What is the main purpose of taking Carozile?
a. reduce blood pressure
b. reduce blood clotting
c. reduce inflammation at joints
d. increase dopamine in the brain

2. How likely is it that scientists will improve upon Carozile in the next year?
a. extremely unlikely
b. unlikely
c. uncertain 

d. likely
e. extremely likely

3. According to scientists' estimates, about how many people will die each year as a result of taking Carozile?
a. $10-50$
b. $400-700$
c. $100-300$
d. $1000-2000$

4. Carozile is known to cause diarrhea in some patients.
a. True
b. False

5. According to scientists' estimates, about how many people at risk will die each year if they do not take Carozile?
a. $50-90$
b. $300-900$
c. $500-800$
d. $2000-4000$

\section{References}

Brunstein, J. C., \& Maier, G. W. (2005). Implicit and self-attributed motives to achieve: Two separate but interacting needs. Journal of Personality and Social Psychology, 89, 205-222.

Brunstein, J. C., Schultheiss, O. C., \& Grässmann, R. (1998). Personal goals and emotional well-being: The moderating role of motive dispositions. Journal of Personality and Social Psychology, 75, 494-508.

Edwards, J. R. (2008). Person-environment fit in organizations: An assessment of theoretical progress. Academy of Management Annals, 2, 167-230.

Emmons, R. A. (1986). Personal strivings: An approach to personality and subjective well-being. Journal of Personality and Social Psychology, 51, $1058-1068$.

Emmons, R. A. (1989). The personal striving approach to personality. In L. A. Pervin (Ed.), Goal concepts in personality and social psychology (pp. 87-126). Hillsdale, NJ: Lawrence Erlbaum.

Emmons, R. A. (1997). Motives and goals. In R. Hogan, J. A. Johnson, \& S. R. Briggs (Eds.), Handbook of personality psychology (pp. 485-512). San Diego, CA: Academic Press.

Emmons, R. A., Diener, E., \& Larsen, R. J. (1986). Choice and avoidance of everyday situations and affect congruence: Two models of reciprocal interactionism. Journal of Personality and Social Psychology, 51, 815-826.

Emmons, R. A., \& McAdams, D. P. (1991). Personal strivings and motive dispositions: Exploring the links. Personality and Social Psychology Bulletin, 17, $648-654$.

Ferguson, M. R., \& Barth, J. (2002). Governors in the legislative arena: The importance of personality in shaping success. Journal of Political Psychology, 23, $787-808$.

Fodor, E. M., Wick, D. P., \& Hartsen, K. M. (2006). The power motive and affective response to assertiveness. Journal of Research in Personality, 40, 598-610.

Harms, P. D., Roberts, B. W., \& Winter, D. G. (2006). Becoming the Harvard man: Person-environment fit, personality development, and academic success. Personality and Social Psychology Bulletin, 32, 851-865.

Harms, P. D., Roberts, B. W., \& Wood, D. (2007). Who shall lead? An integrative personality approach to the study of the antecedents of status in informal social organizations. Journal of Research in Personality, 41, 689-699.

Hermann, M. G. (1980). Explaining foreign policy behavior using the personal characteristics of political leaders. International Studies Quarterly, 24, 7-46.

Igreja, I., Zuroff, D. C., Koestner, R., Saltaris, C., Brouillette, M.-J., \& Lalonde, R. (2000). Social motives, social support, and distress in gay men differing in HIV status. Journal of Research in Personality, 34, 287-304.

Kehr, H. M. (2004). Implicit/explicit motive discrepancies and volitional depletion among managers. Personality and Social Psychology Bulletin, $30,315-327$.

King, L. A. (1995). Wishes, motives, goals, and personal memories: Relations of measures of human motivation. Journal of Personality, 63, $985-1007$.

Koestner, R., Weinberger, J., \& McClelland, D. C. (1991). Task-intrinsic and social-extrinsic sources of arousal for motives assessed in fantasy and self-report. Journal of Personality, 59, 57-82.

Langner, C. A., \& Winter, D. G. (2001). The motivational basis of concessions and compromise: Archival and laboratory studies. Journal of Personality and Social Psychology, 81, 711-727.

Maner, J. K., Gailliot, M. T., Butz, D., \& Peruche, B. M. (2007). Power, risk, and the status quo: Does power promote riskier or more conservative decision making? Personality and Social Psychology Bulletin, 3, 451-462.

McAdams, D. P. (1982). Intimacy motivation. In A. J. Stewart (Ed.), Motivation and society (pp. 133-171). San Francisco: Jossey-Bass.

McAdams, D. P., Healy, S., \& Krause, S. (1984). Social motives and patterns of friendship. Journal of Personality and Social Psychology, 47, 828-838.

McClelland, D. C. (1961). The achieving society. Princeton, NJ: Van Nostrand.

McClelland, D. C. (1970). The two faces of power. Journal of International Affairs, 24, 29-47.

McClelland, D. C. (1975). Power: The inner experience. New York: Irvington.

McClelland, D. C. (1985). Human motivation. Glenview, IL: Scott, Foresman.

McClelland, D. C., \& Boyatzis, R. E. (1982). The leadership motive pattern and long-term success in management. Journal of Applied Psychology, 67, 737-743.

McClelland, D. C., Koestner, R., \& Weinberger, J. (1989). How do self-attributed and implicit motives differ? Psychological Review, 96, $690-702$.

McClelland, D. C., \& Watson, R. I. (1973). Power motivation and risk-taking behavior. Journal of Personality, 41, $121-139$.

McClelland, D. C., \& Wilsnack, S. C. (1972). The effects of drinking on thoughts about power and restraint. In D. C. McClelland, W. N. Davis, R. Kalin, \& E. Wanner (Eds.), The drinking man (pp. 123-141). New York: Free Press.

Mischel, W., \& Shoda, Y. (1995). A cognitive-affective system theory of personality: Reconceptualizing situations, dispositions, dynamics, and invariance in personality structure. Psychological Review, 102, 246-268.

O'Reilly, C. A., III, Chatman, J., \& Caldwell, D. F. (1991). People and organizational culture: A profile comparison approach to assessing person-organization fit. Academy of Management Journal, 34, 487-516.

Pang, J. S., \& Schultheiss, O. C. (2005). Assessing implicit motives in U.S. college students: Effects of picture type and position, gender and ethnicity, and cross-cultural comparisons. Journal of Personality Assessment, 85, 280-294.

Pervin, L. A. (1968). Performance and satisfaction as a function of individual environment fit. Psychological Bulletin, 69, 56-68. 
Peterson, B. E., Winter, D. G., \& Doty, R. M. (1994). Laboratory tests of a motivational-perceptual model of conflict escalation. Journal of Conflict Resolution, 38 , 719-748.

Roberts, B. W., \& Pomerantz, E. M. (2004). On traits, situations, and their integration: A developmental perspective. Personality and Social Psychology Review, $8,402-416$.

Roberts, B. W., \& Robins, R. W. (2004). A longitudinal study of person-environment fit and personality development. Journal of Personality, 72, 89-110.

Schultheiss, O. C. (2001). An information processing account of implicit motive arousal. In M. L. Maehr \& P. Pintrich (Eds.). Advances in motivation and achievement (Vol. 12, pp. 1-41). Greenwich, CT: JAI Press.

Schultheiss, O. C., \& Brunstein, J. C. (2002). Inhibited power motivation and persuasive communication: A lens model analysis. Journal of Personality, 70 , 553-582.

Schultheiss, O. C., Campbell, K. L., \& McClelland, D. C. (1999). Implicit power motivation moderates men's testosterone responses to imagined and real dominance success. Hormones and Behavior, 36, 234-241.

Schultheiss, O. C., \& Pang, J. S. (2007). Measuring implicit motives. In R. W. Robins, R. C. Fraley, \& R. Krueger (Eds.), Handbook of research methods in personality psychology (pp. 322-344). New York: Guilford Press.

Shah, J., Higgins, E. T., \& Friedman, R. S. (1998). Performance incentives and means: How regulatory focus influences goal attainment. Journal of Personality and Social Psychology, 74, 285-293.

Spangler, W. D. (1992). Validity of questionnaire and TAT measures of need for achievement: Two meta-analyses. Psychological Bulletin, 112, 140-154.

Spangler, W. D., \& House, R. J. (1991). Presidential effectiveness and the leadership motive profile. Journal of Personality and Social Psychology, 60, $439-455$.

Tetlock, P. E., \& Boettger, R. (1994). Accountability amplifies the status quo effect when change creates victims. Journal of Behavioral Decision Making, 7, 1-23.

Thomas, M., Goleman, D., \& Goldstein, R. (1972). Scoring manual for personal and social power concerns. In D. C. McClelland, W. N. Davis, R. Kalin, \& E. Wanner (Eds.), The drinking man (pp. 351-356). New York: Free Press.

Walsh, W. B., Craik, K., \& Price, R. H. (2000). Person-environment psychology (2nd ed.). Mahwah, NJ: Lawrence Erlbaum.

Walters, A. E., Stuhlmacher, A. F., \& Meyer, L. L. (1998). Gender and negotiator competitiveness: A meta-analysis. Organizational Behavior and Human Decision Processes, 76, 1-29.

Winter, D. G. (1973). The power motive. New York: The Free Press.

Winter, D. G. (1987). Leader appeal, leader performance, and the motive profiles of leaders and followers: A study of American presidents and elections. Journal of Personality and Social Psychology, 52, 196-202.

Winter, D. G. (1988). The power motive in women-and men. Journal of Personality and Social Psychology, 54, 510-519.

Winter, D. G. (1991). Measuring personality at a distance: Development of an integrated system for scoring motives in running text. In D. J. Ozer, J. M. Healy, \& A. J. Stewart (Eds.). Perspectives in personality: Approaches to understanding lives (Vol. 3b, pp. 59-89). Philadelphia, PA: Jessica Kingsley.

Winter, D. G. (1992). Power motivation revisited. In C. P. Smith (Ed.), Motivation and personality: Handbook of thematic content analysis (pp. 301-310). Cambridge: Cambridge University Press.

Winter, D. G. (2000). Power, sex, and violence: A psychological reconstruction of the 20th century and an intellectual agenda for political psychology. Political Psychology, 21, 383-404.

Winter, D. G. (2002). Motivation and political leadership. In O. Feldman \& L. O. Valenty (Eds.), Political leadership for the new century: Personality and behavior among American leaders (pp. 25-47). Westport, CT: Greenwood.

Winter, D. G. (2005). Things I've learned about personality from studying political leaders at a distance. Journal of Personality, 73, 557-584.

Winter, D. G., \& Barenbaum, N. B. (1985). Responsibility and the power motive in men and women. Journal of Personality, 53, 335-355.

Winter, D. G., John, O. P., Stewart, A. J., Klohnen, E. C., \& Duncan, L. E. (1998). Traits and motives: Toward an integration of two traditions in personality research. Psychological Review, 105, 230-250.

Winter, D. G., \& Stewart, A. J. (1978). The power motive. In H. London \& J. E. Exner (Eds.), Dimensions of personality (pp. 391-448). New York: Wiley.

Woike, B., Mcleod, S., \& Goggin, M. (2003). Implicit and explicit motives influence accessibility to different autobiographical knowledge. Personality and Social Psychology Bulletin, 29, 1046-1055.

Zurbriggen, E. L. (2000). Social motives and cognitive power-sex associations: Predictors of aggressive sexual behavior. Journal of Personality and Social Psychology, 78, 559-581. 